\title{
Phytosterols in Tobacco: Quantitative Analysis and Fate in Tobacco Combustion*
}

\author{
by Invin Schmeltz, Anneli de Paolis, and Dietrich Hoffmann \\ Division of Environmental Carcinogenesis, Naylor Dana Institute for Disease Prevention, \\ American Health Foundation, Valhalla, N. Y., USA
}

\section{INTRODUCTION}

The phytosterols of tobacco have been the subject of a number of investigations $(1-12)$ which, for the most part, have been concerned with techniques of isolation and identification; thus cholesterol, campesterol, stigmasterol, and $\beta$-sitosterol have been shown to be the characteristic sterols of tobacco. Earlier reports alluded to the presence of $\gamma$-sitosterol in tobacco $(1,13)$; however, subsequent studies showed this material to be a mixture of $\beta$-sitosterol and campesterol rather than a single compound $\left(1_{4}-16\right)$. One report (13) cited the presence of ergosterol in tobacco.

The phytosterols can influence the chemical nature of tobacco smoke in two ways: by direct transfer into the smoke or by pyrolytic conversion to other products which also enter the smoke stream. To determine the extent to which the first of these processes occurs, a relatively simple procedure was needed for the analysis of the sterols. Methods utilized previously can best be described as semi-quantitative. Grunwald (9) and Cheng (xo), for example, made use of the technique of precipitating the sterols with digitonin prior to analysis. A similar method was described earlier by Stedman (4). The obvious disadvantages of this technique, which we encountered, are losses due to derivatization and subsequent decomposition of the digitonides. Although previous workers $(9,10)$ also studied the transfer of phytosterols from leaf to smoke, they failed to consider the sidestream portion of the smoke - which actually consumes more tobacco in its formation than does the mainstream (17).

In the procedure described herein; preparation of sterol-digitonides is unnecessary, the sterols being isolated and analyzed as such. ${ }^{14} \mathrm{C}$-labelled cholesterol is used as internal standard to calculate recoveries, and to determine absolute amounts of sterols. GeI permeation chromatography of tobacco or smoke extracts, containing tracer, results in sterol-rich eluates

\footnotetext{
- Chemical Studies on Tobrceo Smoke, XXXI. Received for publication: 26th February, 1973.

Parts of this study were presented at the 28th Tobseco Chemists' Research Conference in Raleigh, N. C., 1974. It was supported in part by National Cancet Institute Contract No. 1-CP-3305 and by an Institutional Grant.
}

suitable for $\mathrm{glc}^{+}$analysis. Identities of glc peaks are made by combined glc/mass spectrometry.

With regard to the influence of the phytosterols on the biological activity of the smoke, pyrolysis studies have shown that sterols give rise to products that are carcinogenic $(18,19)$ and contain polynuclear aromatic hydrocarbons $(19,20)$, including alkylchrysenes (21). However, pyrolysis is merely one of the processes occurring in a burning cigarette $(22,23)$, and may not be an accurate reflection of the total picture. In the present study, therefore, in addition to developing a new analytical method for the phytosterols of tobacco, we explore their fate in a burning cigarette.

\section{EXPERIMENTAL}

\section{Apparatus}

Cigarettes and little cigars were smoked on a 20-port automated Phipps and Bird smoking machine for the collection of mainstream smoke, and on a single-port Borgwaldt piston-type machine (24) in conjunction with a specially designed smoke chamber (25) for the collection of sidestream smoke. The apparatus for impregnating cigarettes with cholesterol $-4^{-14} \mathrm{C}$, a syringe-type applicator, was developed and made ayailable by $W . L$. Maddox and M. R. Guerin of the Oak Ridge National Laboratories, Oak Ridge, Tenn. A Hewlett-Packard gas chromatograph Model 7620A with flame-ionization detector was used for the qualitative and quantitative analysis. The $\beta$-radiation of the ${ }^{14} \mathrm{C}$-labelled internal standard was counted in a Nuclear Chicago Isocap 300 Scintillation System. Infrared spectra were recorded on a Perkin-Elmer Model $2 x$. The mass spectra were obtained on an AEI-MS-3o combined gc-ms** instrument by the Shrader Analytical and Consulting Laboratories, Inc. (Detroit, Mich.).

\section{Reagents}

All organic solvents were spectrograde; the other chemicals were reagent grade. The reference phytosterols and cholestane were obtained from Applied Science Laboratories, State College, Pa. Sephadex

\footnotetext{
4* gas dromatography - mass spectrometry.

+ gas-liquid dromatography.
} 
LH-20 was purchased from Pharmacia Fine Chemicals, Piscataway, N. J., and cholesterol-4-4 ${ }^{-14} \mathrm{C}$ (specific activity: $19.4 \mathrm{mci} / \mathrm{mM}$ ) from Amersham/Searle, Arlington Heights, Ill. PPO (2,5-diphenyloxazole, 8.0 g) and POPOP ( $p$-bis[2-(5-phenyloxazole)]benzene, $0.1 \mathrm{~g}$ ) in $2000 \mathrm{ml}$ toluene (Fisher Chemicals) was used as scintillation solution for measuring the $\beta$-activity of cholesterol $-4^{-14} \mathrm{C}$; efficiency for the unquenched sample was $74.0 \%$.

\section{Smoking Products}

Commercial U. S. nonfilter cigarettes $(85 \mathrm{~mm})$ and experimental little cigars (without filters, $85 \mathrm{~mm}$, Consolidated Cigar Corp.) were used to obtain the analytical data. The cigarettes and cigars were weightselected (average weight of 200 cigarettes or cigars, $\pm 20 \mathrm{mg}$ ) and were stored in a constant humidity and temperature chamber (relative humidity $60 \%, 22^{\circ} \mathrm{C}$ ) for at least 24 hours prior to smoking.

\section{Procedure: Isolation of Free Sterols}

From Tobacco: The tobacco from 20 cigarettes or little cigars was ground in a Waring blender and extracted with refluxing methanol $(600 \mathrm{ml})$ in a Soxhlet extractor for 24 hours. As internal standard, $1.0 \mathrm{ml}$ of a solution of cholesterol-4-14 $\mathrm{C}\left(1.0 \mu \mathrm{g}, \cong 10^{6} \mathrm{dpm}^{*}\right)$ in benzene was added to the methanol solution. The solution was cooled to room temperature; the precipitated material, primarily paraffins, was filtered, and the filtrate was concentrated on a rotary evaporator. Water was added to the methanolic concentrate to achieve a methanol to water ratio of 4 to $I$ (in $100 \mathrm{ml}$ ). The methanolwater solution was then extracted with $n$-hexane $(3 \times$ $150 \mathrm{ml})$. The combined hexane layers were backextracted with $90 \%$ methanol $(2 \times 50 \mathrm{ml})$ and evaporated to dryness under reduced pressure. The residue was redissolved in a small amount of chloroform (ca. $5 \mathrm{ml}$ ) for application to a column of Sephadex LH-2O.

From Cigarette or Cigar Smoke: For analysis of mainstream smoke, twenty cigarettes or little cigars, weightselected and pre-humidified, were smoked through a Cambridge filter (CM-113) (5 cigarettes or little cigars per filter) under standard conditions (one $35 \mathrm{ml}$ puff of 2 seconds duration every minute to a butt length of $23 \mathrm{~mm}$ ). For analysis of sidestream smoke, air was continually passed through the smoking chamber (25) at a rate of $25 \mathrm{ml} / \mathrm{s}$, and the smoke particulates were collected on a Cambridge filter. In either case, the filters loaded with particulate matter were broken up and soaked in acetone overnight, together with the acetone washings of the filter holders. The suspension of smoke particulates, to which $1.0 \mu \mathrm{g}$ of cholesterol$4^{-14} \mathrm{C}$ had been added, was filtered, and the filtrate was evaporated to dryness. The resulting residue was dissolved in chloroform, and an appropriate aliquot $(25 \%)$ was taken for chromatography on Sephadex LH-20.

\section{Isolation and Analysis of Total Sterols}

The methanolic extract of tobacco or the acetone extract of tobacco smoke particulates (both containing ${ }^{14}$ C-labelled internal standard) was evaporated to dryness. The residue was then refluxed, for 20 hours, in a solution of $95 \%$ ethanol containing $0.65 \mathrm{ml}$ of concentrated sulfuric acid. Hydrolysis of the steryl esters was completed by adding $75 \mathrm{ml}$ of a solution of $95 \%$ ethanol containing $10 \% \mathrm{KOH}$ and refluxing for an additional 30 minutes. The resulting mixture was neutralized, concentrated, and worked up as for free sterols.

\section{Gel Permeation Chromatography}

Sephadex LH-20 was swollen in chloroform overnight $(75 \mathrm{~g})$; the resulting thick slurry was poured into a

Figure 1. Representative gas chromatograms of phytosterols.
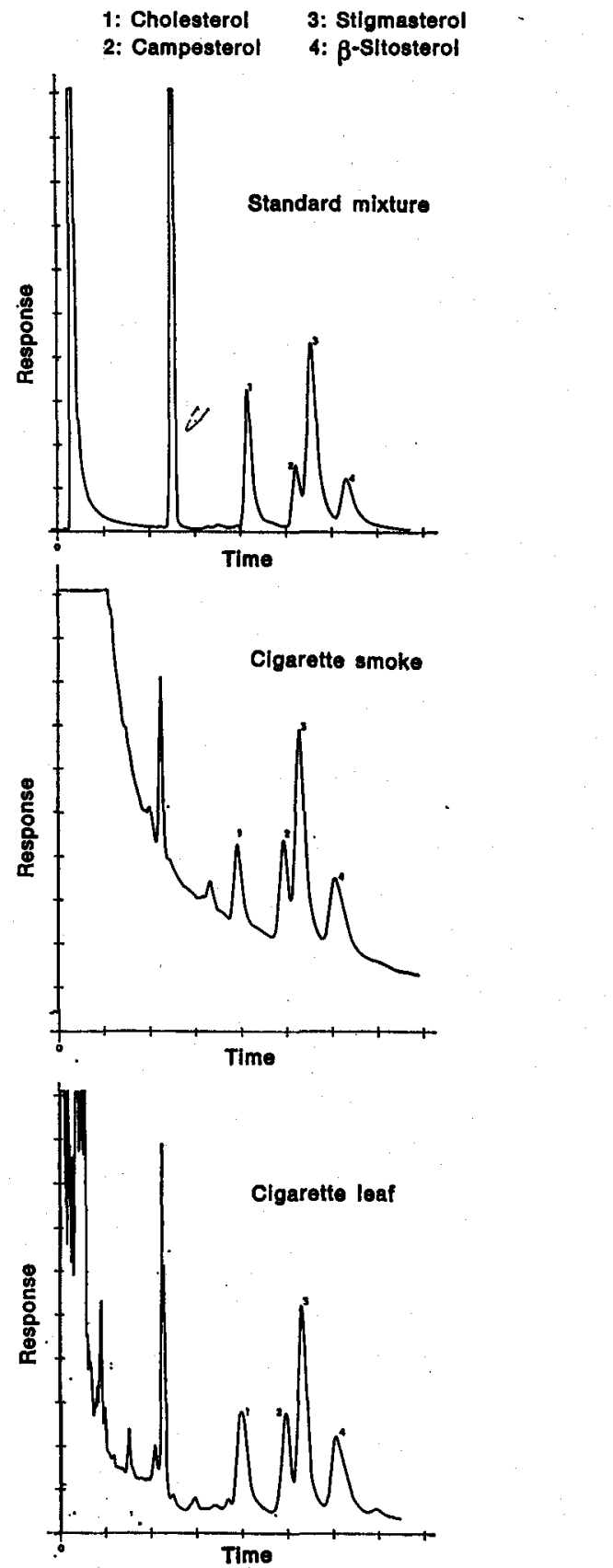
Table 1. Gas-liquid chromatography (glc) of phytosterols: Relative retention timesa.

\begin{tabular}{l|c|c|c|c|c}
\cline { 3 - 6 } & \multirow{2}{*}{$\begin{array}{c}\text { Stan- } \\
\text { dard } \\
\text { mixture }\end{array}$} & \multicolumn{2}{|c|}{ Cigar } & \multicolumn{2}{c}{ Cigarette } \\
\cline { 3 - 6 } & & Leaf & Smoke & Leaf & Smoke \\
\hline Cholestaneb & 1.00 & 1.00 & 1.00 & 1.00 & 1.00 \\
Cholesterol & 1.64 & 1.67 & 1.67 & 1.67 & 1.65 \\
Campesterol & 2.06 & 2.08 & 2.08 & 2.09 & 2.07 \\
Stigmasterol & 2.21 & 2.23 & 2.22 & 2.23 & 2.22 \\
$\beta$-Sitosterol & 2.52 & 2.53 & 2.52 & 2.53 & 2.50 \\
\hline
\end{tabular}

a: Relative to cholestane (retention time: $14.58 \mathrm{~min}$ ).

Conditions: Column temperature: $2650 \mathrm{C}$

Injector temperature: $2800 \mathrm{C}$.

Detector temperature: $2800 \mathrm{C}$ (FID).

Flow rate: $\quad 43 \mathrm{mi} / \mathrm{min}$

Column packing: $\quad 5 \%$ SE-30 on $60 / 80$ mesh Chromosorb $W$; all glass (11 ft. $\times 0.125$ in.).

b: Internal standard.

$2 \times 105 \mathrm{~cm}$ glass column with a void volume of $80 \mathrm{ml}$. After application of the chloroform solution of tobacco or smoke isolate, the column was eluted with chloroform at a flow rate of $0.5 \mathrm{ml} / \mathrm{min}$, and fractions $(3 \mathrm{ml})$ were collected. Fractions 28-60 contained mainly paraffins $\left(C_{25}-C_{35}\right), \alpha$-tocopherol, and amyrins. The major portion of the radioactivity (due to the internal standard) was found in fractions 61-70 (@ 65-75\% recovery) containing the phytosterols.

Shorter columns $(2 \times 33 \mathrm{~cm})$ of Sephadex were also used and found to be satisfactory. In these cases, the void volume was $12 \mathrm{ml}$; the flow rate was $0.3 \mathrm{ml} / \mathrm{min}$, and $2 \mathrm{ml}$ fractions were collected. Fractions 16-26 contained the major radioactivity ( $80-90 \%$ of total) and the phytosterols.

With either modification, the radioactive fractions were pooled, and the pooled fractions were concentrated for glc analysis. Recoveries were determined by counting appropriate aliquots.

\section{Gas Chromatography}

Phytosterol concentrates from tobacco and tobacco smoke and standard mixtures were resolved at $265^{\circ} \mathrm{C}$ on an $11 \mathrm{ft} . \times 0.125$ in. glass column (with glass-lined injector port) packed with $5 \%$ SE-30 on Chromosorb $W$ (mesh 60/80). Helium was used as a carrier gas with a flow rate of $43 \mathrm{ml} / \mathrm{min}$. Other conditions were: column temperature, $265^{\circ} \mathrm{C}$; injector temperature, $280^{\circ} \mathrm{C}$; detector temperature, $280^{\circ} \mathrm{C}$. Retention data for the phytosterols are given in Table 1 , and representative gas chromatograms are shown in Figure $I$.

\section{Qualitative and Quantitative Analysis}

Peak identities were established by the use of combined $\mathrm{glc} / \mathrm{ms}$ in addition to retention times. For quantitative analysis, a known amount of cholestane was added, as a second internal standard, to the phytosterol fractions in ethyl acetate, and aliquots were subjected to glc under the conditions described above. Peak areas of the resulting chromatograms were measured, and corresponding weights were obtained by use of appropriate calibration curves (26).

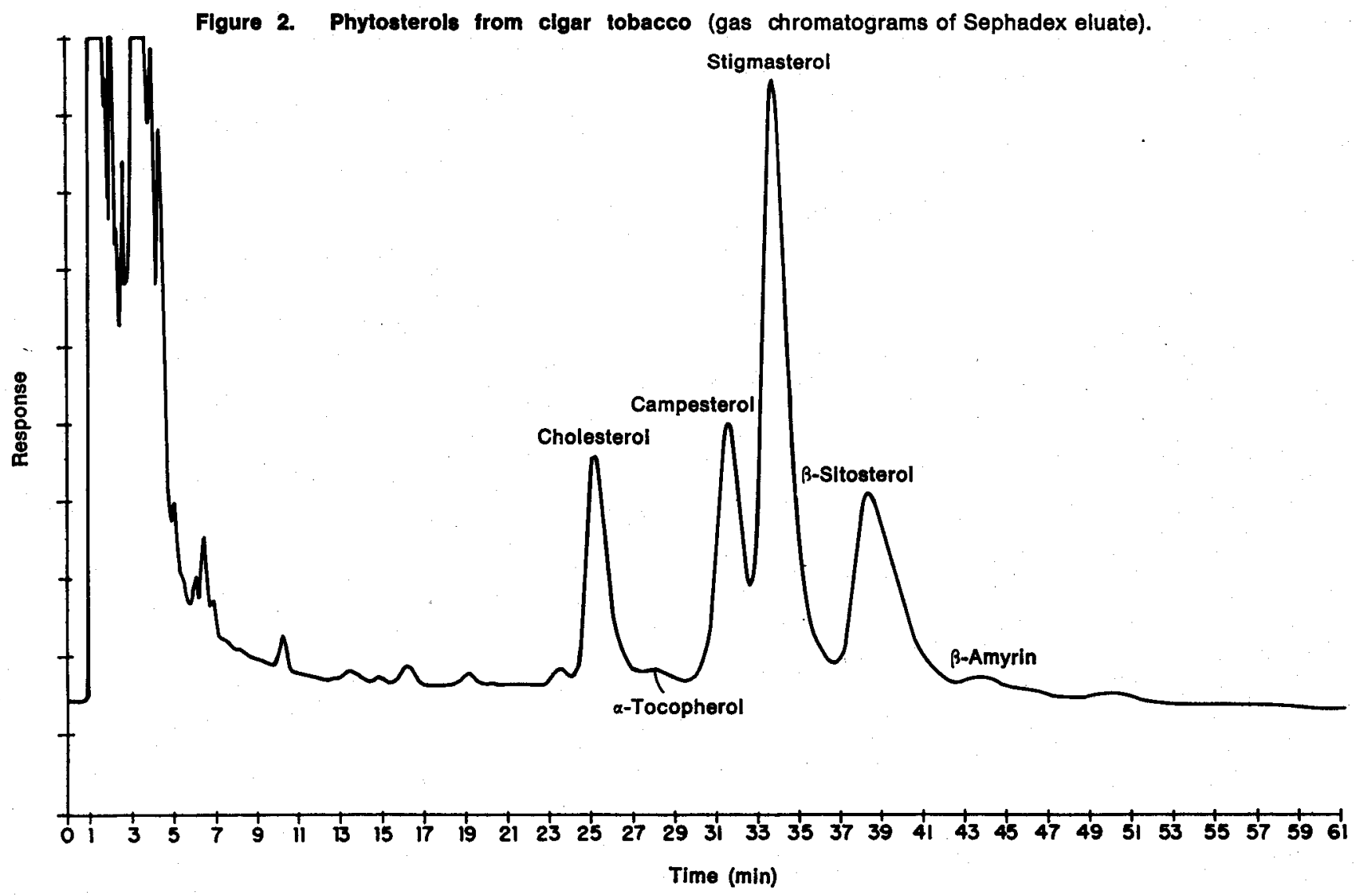




\section{RESULTS AND DISCUSSION}

\section{Phytosterols in Tobacco}

Sephadex chromatography of the "terpenoid fraction" of tobacco yielded an eluate, which on glc analysis showed four major peaks (Fig. 2). Further analysis by combined glc-mass spectrometry showed these peaks to be cholesterol, campesterol, stigmasterol, and $\beta$ sitosterol*. Retention times were consistent with peak assignments (Table 1 ); smaller peaks eluting between cholesterol and campesterol and after $\beta$-sitosterol were shown by mass spectra and retention times to be $\alpha$-tocopherol and $\beta$-amyrin, respectively.

The mass spectra obtained for the major peaks were unexceptional and compared well to spectra of reference sterols. Characteristic ions were produced in each case, including the molecular ion (M), M-15, M-18, $M-(15+18), M-($ side chain), in addition to the other expected ions in the intermediate and lower mass regions of the spectra. Inasmuch as the four sterols differ only in the nature of the side chain, they all give essentially identical fragmentation patterns once the side chain is removed on electron-impact, that is, ions with masses of 273, 255, 231, 213, and so on. Detailed spectra have been published $(27,28)$.

These initial studies led us to develop a quantitative method for the analysis of the free sterols of tobacco (Fig. 3) based on Sephadex chromatography of a to-
Table 2. Unbound phytosterols in tobaccoa $(\mu / g / g)$.

\begin{tabular}{lc|ccc|c}
\hline $\begin{array}{c}\text { No. of } \\
\text { analysis }\end{array}$ & Cholesterol & $\begin{array}{c}\text { Campe- } \\
\text { sterol }\end{array}$ & $\begin{array}{c}\text { Stigma- } \\
\text { sterol }\end{array}$ & $\beta$-Sitosterol \\
\hline 1 & 143 & 207 & 536 & 309 \\
2 & 161 & 233 & 591 & 309 \\
3 & 157 & 220 & 582 & 336 \\
4 & 157 & 244 & 626 & 361 \\
Average & 155 & 226 & 584 & 329 \\
\hline $\begin{array}{l}\text { Standard } \\
\text { deviation }\end{array}$ & 8 & 16 & 37 & 25 \\
$\begin{array}{l}\text { Deviation } \\
\text { coefficient }(\%)\end{array}$ & 5.1 & 7.1 & 6.4 & 7.6 \\
\hline
\end{tabular}

a: Cigar tobacco, Manila variety.

Moisture content: 11:7\%.

Values were calculated by the isotope-dilution method; recoveries: $65-75 \%$.

bacco isolate (to which ${ }^{14} \mathrm{C}$-cholesterol is added as internal standard) followed by glc of the radioactive portion of the eluate. The gas chromatogram obtained and used for quantitative analysis is identical to that shown (Fig. 2).

The method was applied to cigar tobacco, and repeated analyses gave the data, summarized in Table 2, for free sterols. In addition, by incorporating acid and alkaline hydrolysis steps into the procedure, we were able to determine total sterols (Table 3). Bound sterols were then determined by difference. Table 4 gives

Figure 3. Scheme for determination of leaf phytosterols.

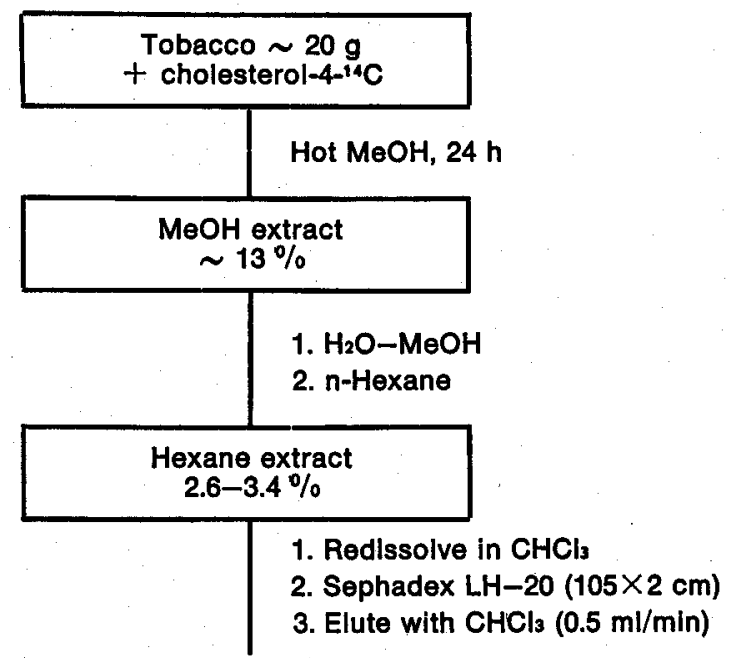

Fractions

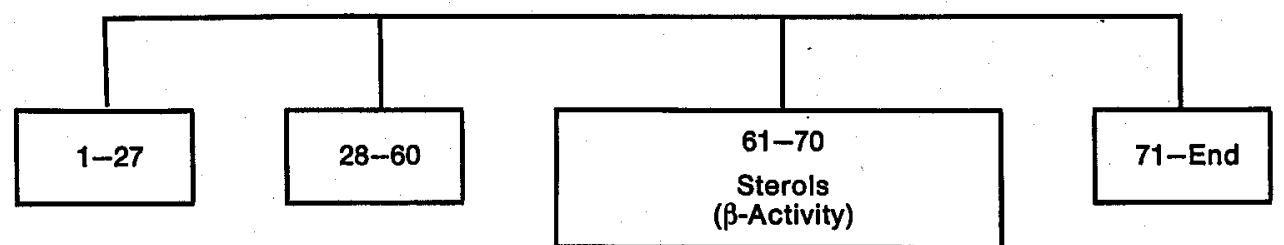

* Detailed mass-spectral analysis did not reveal any phytosterol other than $\beta$-sitosterol under the last major peak (Fig. 2). 
Table 3. Total phytosterols in tobaccoa $(\mu \mathrm{g} / \mathrm{g})$.

\begin{tabular}{l|c|c|c|c}
\hline $\begin{array}{c}\text { No. of } \\
\text { analysls }\end{array}$ & Cholesterol & $\begin{array}{c}\text { Campe- } \\
\text { sterol }\end{array}$ & $\begin{array}{c}\text { Stigma- } \\
\text { sterol }\end{array}$ & $\beta$-Sitosterol \\
\hline 1 & 251 & 477 & 966 & 681 \\
2 & 305 & 417 & 977 & 601 \\
3 & 271 & 377 & 1133 & 627 \\
4 & 316 & 486 & 914 & 646 \\
Average & 286 & 439 & 998 & 639 \\
\hline Standard & 30 & 52 & 94 & 34 \\
deviation & 30 & & & \\
Deviation & & 11.8 & 9.5 & 5.3 \\
\hline
\end{tabular}

a: Cigar tobacco, Manlla variety.

Moisture content: $11.7 \%$.

Values were calculated by the isotope-dilution method, recoveries: $65-75 \%$.

Total phytosterols = unbound sterois + steryl esters + steryl glycosides.

concentration levels of free, bound, and total sterols obtained by application of the method to tobacco from commercial cigarettes and little cigars.

To put the foregoing results into perspective, total phytosterols constitute about $10 \%$ of the weight of the "terpenoid fraction of tobacco", and about $0.2 \%$ of the tobacco itself. As reported previously (9), stigmasterol is the major phytosterol, comprising $0.06 \%$ (bound plus unbound) of tobacco. Cholesterol accounts for more than $10 \%$ of the total phytosterol content, and for about $0.02 \%$ of the tobacco.

Gel permeation chromatography of tobacco fractions has previously been reported by Wall and co-workers (7). By using this method in conjunction with counter current distribution, they isolated the sterols of tobacco. However, their procedure was not quantitative and was, moreover, rather involved. It appears unnecessary, on the basis of the present studies, to conduct extensive preliminary fractionation of tobacco isolates to obtain quantitative amounts of sterols and possibly amyrins and tocopherols.

As for ergosterol, our studies indicate that this compound is highly unstable, and not amenable to glc, even on glass columns. Trimethylsilylation of the authentic material, however, enables it to be gaschromatographed satisfactorily, and when added to a standard mixture of silylated sterols is found to elute between cholesterol and campesterol. Silylated sterol fractions from tobacco and tobacco smoke fail to exhibit a corresponding peak.

\section{Phytosterols in Tobacco Smoke}

The same method as that used for leaf sterols was essentially applied to tobacco smoke (Fig. 4). Recoveries were somewhat higher for the smoke sterols ( $80-90 \%)$. Pertinent data (Tables 5 and 6) are presented for the mainstream and sidestream smoke of the commercial cigarette and little cigar used throughout this study. This is the first report of levels of sterols in the sidestream smoke of a cigarette and a cigar.
Table 4. Phytosterols In clgarette and cigar tobaccoa $(\mu \mathrm{g} / \mathrm{g})$.

\begin{tabular}{lcr|c}
\cline { 2 - 4 } & $\begin{array}{c}\text { Free } \\
\text { sterols }\end{array}$ & $\begin{array}{c}\text { Bound } \\
\text { sterols }\end{array}$ & $\begin{array}{c}\text { Free \& bound } \\
\text { sterols }\end{array}$ \\
\hline Cholesterol & \multicolumn{2}{c}{ Cigarette blend $b$} \\
Campesterol & 129 & 45 & 174 \\
Stigmasterol & 197 & 131 & 328 \\
$\beta$-Sitosterol & 480 & 94 & 574 \\
Totals & 288 & 181 & 469 \\
& 1094 & 451 & 1545 \\
Cholesterol & \multicolumn{4}{c}{ Clgar fillerc } & \\
Campesterol & 155 & 131 & 286 \\
Stigmasterol & 226 & 213 & 439 \\
$\beta$-Sitosterol & 584 & 414 & 998 \\
Totals & 329 & 310 & 639 \\
\hline
\end{tabular}

a: By isotope-dilution method.

b: Commercial blend (U.S.); moisture: $10.4 \%$.

c: Manila variety; moisture: $11.7 \%$

Table 5. Major phytosterols In cigarette smokea $(\mu \mathrm{g} /$ cigarette).

\begin{tabular}{|c|c|c|c|}
\hline & Free & Bound & Free \& bound \\
\hline \multicolumn{4}{|c|}{ Mainstream } \\
\hline Cholesterol & $14.2( \pm 9 \%)$ & 7.8 & 22.0 \\
\hline Campesterol & $24.5( \pm 7.5 \%)$ & 18.2 & 42.7 \\
\hline Stigmasterol & $53.0( \pm 9 \%)$ & 25.0 & 78.0 \\
\hline$\beta$-Sitosterol & $37.0( \pm 10 \%)$ & 22.3 & 59.3 \\
\hline Totals & 129.0 & 73.3 & 202.0 \\
\hline \multicolumn{4}{|c|}{ SIdestream } \\
\hline Cholesterol & 11 & 7.8 & 18.8 \\
\hline Campesterol & 22 & 3.8 & 25.8 \\
\hline Stigmasterol & 43 & 10.6 & 53.6 \\
\hline$\beta$-Sitosterol & 28 & 0 & 28.0 \\
\hline Totals & 104 & 22.2 & $\overline{126.2}$ \\
\hline
\end{tabular}

a: Calculated by isotope-dllution; recoveries: $80-90 \%$. U.S. commerclal, nonfilter clgarette, $85 \mathrm{~mm}, 1.1 \mathrm{~g}$. Figures in parentheses represent deviation coefficients.

Table 6. Phytosterols In clgar smokea ( $\mu$ g/cigar).

\begin{tabular}{lr|r|r|r} 
& \multicolumn{3}{c|}{ Mainstream } & Sidestream \\
\cline { 2 - 5 } & $\begin{array}{c}\text { Un- } \\
\text { boundb }\end{array}$ & Boundc & Totalb & Totalb \\
\hline Cholesterol & 25.0 & 12.4 & 37.4 & 21.7 \\
Campesterol & 45.0 & 11.4 & 56.4 & 43.8 \\
Stigmasterol & 100.0 & 15.8 & 115.8 & 94.2 \\
$\beta$ S-Sitosterol & 57.0 & 6.0 & 63.0 & 49.6 \\
Total sterols & 227.0 & 45.6 & 272.6 & 209.3 \\
\hline
\end{tabular}

a: Experimental little cigar, Manila tiller, RTS (reconstituted tobacco sheet) wrapper. Weight: $1.045 \mathrm{~g} / \mathrm{cigar}$.

b: Determined experimentally.

c: By difference. 
Figure 4. Scheme for determinatlon of smoke phytosterols.

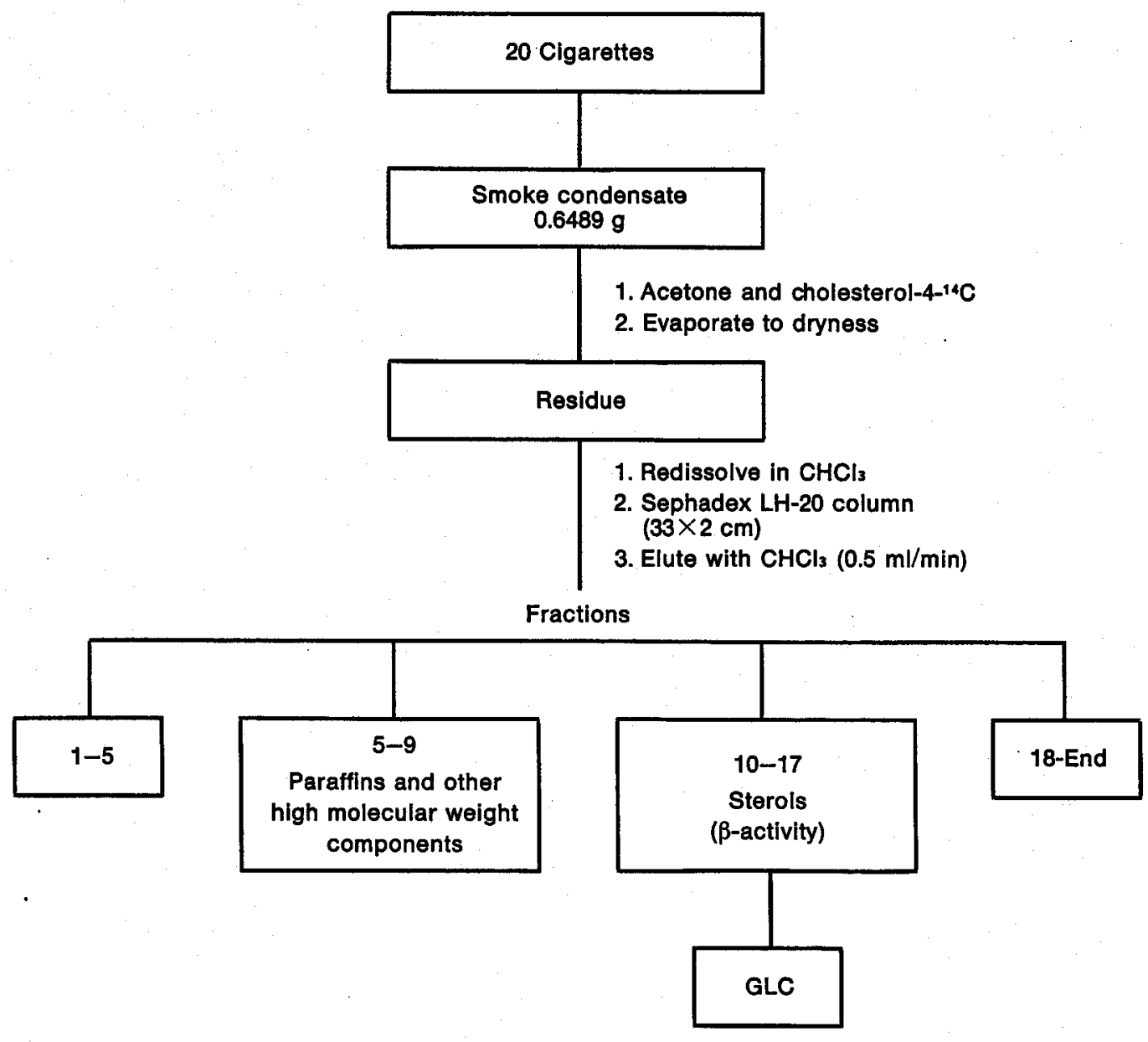

Transfer rates of sterols (Table 7) from leaf into smoke (mainstream and sidestream) can be calculated from the foregoing data. It is evident that much of the sterol content in leaf cannot be accounted for, since only about $20 \%$ is transferred, as sterols, into the smoke. Free sterols in smoke can ostensibly arise

Table 7. Transfer rates of tree and bound sterols into smoke $(\%)$.

\begin{tabular}{|l|l|l}
\hline Mainstream & Sidestream & Total smoke \\
\hline
\end{tabular}

\begin{tabular}{lcrr} 
Cholesterol & 13.9 & 12.0 & 25.9 \\
Campesterol & 14.4 & 8.7 & 23.1 \\
Stigmasterol & 14.9 & 10.3 & 25.2 \\
$\beta$-Sitosterol & 13.9 & 6.6 & 20.5 \\
\hline All sterols & 14.3 & 9.0 & 23.3 \\
& \multicolumn{2}{c}{ Cigar } & \\
Cholesterol & 13.1 & 7.6 & 20.7 \\
Campesterol & 12.8 & 10.0 & 22.8 \\
Stigmasterol & 11.6 & 9.4 & 21.0 \\
$\beta$-Sitosterol & 9.9 & 7.8 & 17.7 \\
All sterols & 11.9 & 8.9 & 20.4 \\
\hline
\end{tabular}

from either free or bound sterols in the leaf, as a result of pyrolytic or hydrolytic degradation. Actually, free sterols comprise $71 \%, 64 \%$, und $82 \%$ of the total sterols present in tobacco, mainstream smoke, and sidestream smoke, respectively.

The fate of the leaf sterols unaccounted for, those not transferred intact into the smoke, is not yet fully resolved. Obviously, they are converted to other compounds (vide infra). A major portion of these may be gaseous hydrocarbons, and appropriate tracer experiments are needed to establish this. Previous speculation (10) that the sidestream smoke contains a significant quantity of sterols (via transfer from leaf) is not borne out by the present study. (Table 8).

Table 8. Total phytosterols: Ratlos of sidestream (SS) to mainstream (MS) concentration levels (SS/MS).

\begin{tabular}{lc|c}
\cline { 2 - 3 } & Cigarette smoke & Cigar smoke \\
\hline Cholesterol & 0.9 & 0.6 \\
Campesterol & 0.6 & 0.8 \\
Stigmasterol & 0.7 & 0.8 \\
B-Sitosterol & 0.5 & 0.8 \\
All sterols & 0.6 & 0.8 \\
\hline
\end{tabular}




\section{Pyrolysis and Tracer Studies}

Pyrolysis studies have demonstrated that at relatively high temperatures $\left(>700^{\circ} \mathrm{C}\right)$. sterols are converted to small amounts of polynuclear aromatic hydrocarbons [PAH $(19-21,29,30)]$. This is to be expected because of the structural features of sterols, and in pyrolyzates of sterols phenanthrene is found as a major constituent of the PAH (20). Although not yet established, a significant portion of the high temperature pyrolysis products of sterols would seem to be gaseous in nature.

In a recent study (31), we pyrolyzed the "terpenoid fraction of tobacco" and found, not surprisingly, that PAH are the characteristic high temperature products here, too. Of course, sterols make up a substantial portion of the terpenoids, but other constituents of this fraction also give rise to PAH upon high-temperature pyrolysis (20). On the other hand, pyrolysis of the terpenoid fraction at lower temperatures (400 to $600^{\circ} \mathrm{C}$ ) yielded pyrolyzates characterized by the presence of alkylnaphthalenes and tetramethylbenzoquinone. The latter compound may arise from $a$-tocopherol in the terpenoid fraction; alkylnaphthalenes may have a variety of precursors, including sterols. Pyrolysis of stigmasterol at $400-600^{\circ} \mathrm{C}$ yielded a "naphthalene" fraction consisting predominantly of naphthalene and 1 - and 2-methylnaphthalene, and much smaller amounts of other alkylnaphthalenes. Mass spectral studies indicated the presence of aryl acetylenes and other simple benzene derivatives as well.

Although it is clear from pyrolysis studies that sterols are converted to $\mathrm{PAH}$ at high temperatures, the demonstration of this phenomenon in a burning cigarette is more difficult. We therefore impregnated cigarettes with dolesterol-4-14 $\mathrm{C}$, madhine-smoked the cigarettes, and fractionated the cigarette " $\operatorname{tar}^{\prime \prime}$ (32). In the fractionation procedure used, the PAH are preferentially taken up by nitromethane and other hydrocarbons by cyclohexane. We found that after the fractionation, the former solvent contained $2 \%$ of the initial radioactivity, indicating that as much as $2 \%$ of the ${ }^{14} \mathrm{C}$ cholesterol may have been converted to PAH during the smoking process. Although this represents a rather small amount of conversion product, it could be rather significant in terms of the PAH levels one finds in cigarette "tar" (31). Nine percent of the initially labelled cholesterol represented conversion products other than PAH, that is, compounds of different polarity that were found to be present in the cyclohexane layer. Further studies are planned, in which the nature of these and other products will be more fully elucidated.

\section{SUMMARY}

The influence of tobacco. phytosterols (cholesterol, campesterol, stigmasterol, $\beta$-sitosterol) on the chemical composition and biological activity of tobacco smoke has been of concern to tobacco chemists. Therefore, a relatively simple method, utilizing a ${ }^{14} \mathrm{C}$-internal standard, dromatography on Sephadex and gas-liquid chromatography, was developed for the quantitative analysis of the phytosterols; this method was applied to the tobacco and smoke (mainstream and sidestream) of cigarettes and cigars to determine the fate of the phytosterols in burning tobacco. About $20 \%$ of the total phytosterol content of tobacco was shown to be transferred intact into the smoke; about $2 \%$ was possibly converted into polynuclear aromatic hydrocarbons. Radioactive tracer and pyrolysis studies were used to determine the nature of the phytosterol degradation products found in the smoke.

\section{ZUSAMMENFASSUNG}

Der Einfluß der Phytosterole des Tabaks (Cholesterol, Campesterol, Stigmasterol, $\beta$-Sitosterol) auf die chemische Zusammensetzung und die biologische Wirksamkeit des Rauches ist ein widhtiges Anliegen der Tabakchemiker. Es wurde deshalb eine relativ einfache Methode entwickelt; durch die die Phytosterole unter Einsatz von Sephadex- und Gas-Flüssig-Chromatographie und Verwendung eines ${ }^{14} \mathrm{C}$-markierten inneren Standards quantitativ bestimmt werden können. Um zu untersuchen, was aus den Phytosterolen im brennenden Tabak wird, wurde das Verfahren auf den Tabak und den Rauch (Haupt- und Nebenstrom) von Cigaretten und Zigarren angewandt. Es zeigte sich, daß vom Gesamtgehalt an Phytosterolen des Tabaks etwa 20\% intakt in den Rauch übergehen und ungefähr $2 \%$ möglicherweise in polycyclische aromatische Kohlenwasserstoffe umgewandelt werden. Mittels radioaktiver Indikatoren und Pyrolysestudien wurde untersucht, wie die im Rauch befindlichen Abbauprodukte der Phytosterole beschaffen sind.

\section{RESUME}

Les dhimistes se sont préoccupés de l'influence des phytostérols du tabac (cholestérol, campestérol, stigmastérol, et $\beta$-sitostérol) sur la composition chimique et l'activité biologique de la fumée. Pour analyser quantitativement les phytostérols, on a développé une méthode relativement simple, basée sur la chromatographie sur Sephadex et la chromatographie en phase gazeuse/liquide, avec un étalon interne de ${ }^{14} \mathrm{C}$. On a appliqué cette méthode au tabac et la fumée de cigarette et de cigare (flux principal et secondaire) pour déterminer le sort des phytostérols durant la combustion du tabac. Environ $20 \%$ des phytostérols tołaux sont transmis intacts dans la fumée; $2 \%$ environ sont convertis probablement en hydrocarbures aromatiques polynucléaires. On a utilisé le marquage radioactif et la pyrolyse pour déterminer la nature des produits de dégradation des phytostérols dans la fumée. 


\section{REFERENCES}

1. Khanolkar, V. R., T. B. Panse, and V. D. Dinekar: Science 122 (1955) 515.

2. Kosak, A. I., J. S. Swinehart, D. Taber, and B. L. van Duuren: Science 125 (1957) 991.

3. Dymicky, M., and R. L. Stedman: Tobacco Sci. 2 (1958) 99.

4. Stedman, R. L., J. D. Grossman, M. Dymicky, and W. Rusaniwskyj: Tobacco Sci. 2 (1958) 117.

5. Rodgman, A., L. C. Cook, and P. H. Latimer, Jr.: Tobacco Sci. 3 (1959) 125.

6. Kallianos, A. G., F. A. Shelburne, R. E. Means, R. K. Stevens, R. E. Lax, and J. D. Mold: Biochemical J. 87 (1963) 596.

7. Cook, C. E., M. E. Twine, C. P. Tallent, J. Harper, G. Hernisch, J. B. Lewis, and M. E. Wall: Phytochem. 8 (1969) 1025.

8. Bolt, A. J. N., and R. E. Clarke: Phytochem. 9 (1970) 819.

9. Grunwald, C., P. L. Davis, and L. P. Bush: J. Agr. Food Chem. 19 (1971) 138.

10. Cheng, L. S.: Beitr. Tabakforsch. 7 (1973) 14.

11. Wynder, E. L., and D. Hoffmann: Tobacco and tobacco smoke, Studies in experimental carcinogenesis; Academic Press, New York, N. Y., 1967.

12. Stedman, R. L.: Chem. Rev. 68 (1968) 153.

13. Dymicky, M., and R. L. Stedman: Tobacco Sci. 3 (1959) 4.

14. Thompson, M. J., E. W. Robbins, and G. L. Baker: Steroids 2 (1963) 505.

15. Nishioka, I., N. Ikekawa, A. Yogi, and T. Kawasaki: Chem. Pharm. Bull. Tokyo 13 (1965) 379.

16. Linde, H., N. Ergenec, and K. Meyer: Helv. Chim. Acta. 49 (1966) 1246.

17. Schmeltz, I., D. Hoffmann, and E. L. Wynder: Preventive Medicine 4 (1975) 66.

18. The health consequences of smoking / A report of the Surgeon General, 1972; U. S. Dept. of Health, Educ., and Welf., Publ. Health Serv. Publ. No. $1723-005 x$.
19. Wynder, E. L., G. F. Wright, and Y. Lam: Cancer 11 (1958) 1140.

20. Schlotzhauer, W. S., and I. Schmeltz: Beitr. Tabakforsch. 5 (1969) 5 .

21. Hecht, S. S., W. E. Bondinell, and D. Hoffmann: J. Natl. Cancer Inst. 53 (1974) 1121.

22. Schmeltz, I., W. S. Schlotzhauer, and E. B. Higman: Beitr. Tabakforsch. 6 (1972) 134.

23. Schlotzhauer, W. S., I. Schmeltz, and S. F. Osman: Chem. Ind. London 1970, 1377.

24. Pillsbury, H. C., C. C. Bright, K. Y. O'Connor, and F. W. Irish: J. Assoc. Off. Anal. Chem. 213 (1969) 458.

25. Brunnemann, K. D., and D. Hoffmann: Food Cosmet. Toxicol. 12 (1974) 115.

26. McNair, H. M., and E. J. Bonnelli: Basic gas chromatography; Consolidated Printers, Berkeley, Calif., 1969.

27. Knights, B. A.: J. Gas Chromatog. 1967, 273.

28. Attaway, D. H., P. Haug, and P. L. Parker: Lipids 6 (1971) 687 .

29. Badger, G. M., J. K. Donnelly, and T. M. Spotswood: Australian J. Chem. 18 (1965) 1249.

30. Van Duuren, B. L.: In: G. James, and T. Rosenthal, eds., Tobacco and health; Thomas, Springfield, Ill., 1962.

31. Schmeltz, I., D. Hoffmann, and E. L. Wynder: Proc: 8th Ann. Conf. Trace Subst. in Environmental Health, Columbia, Mo., 1974, D. D. Hemphill, ed., pp. 281-295.

32. Hoffmann, D., G. Rathkamp, K. D. Brunnemann, and E. L. Wynder: Sci. Total Environ. 2 (1973) 151.

The authors' address:

Division of Environmental Carcinogenesis, Naylor Dana Institute for Disease Prevention, American Health Foundation, Valhalla, N. Y., 10595, USA. 